\title{
Effect of Non-Dominant Resistance Training for Unilateral Athletes on Physical Balance and Isokinetic Muscular Function
}

\author{
Gyeo Rea Ui Bit Jung ${ }^{1 *}$, Kyu Min Park ${ }^{1 *}$, Sunghwun Kang ${ }^{1 * *}$ \\ ${ }^{\prime}$ Laboratory of Exercise Physiology, Department of Sport Science, Kangwon National University, Korea \\ *These two authors contributed equally to this work
}

Received: July 30, 2019

Accepted: September 21, 2019

Published online: October 31, 2019

Keywords:

Isokinetic Muscular Function

Non-dominant Resistance

Training

Unilateral Sports
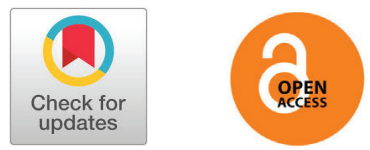

\section{ABSTRACT}

OBJECTIVES This study aimed investigates the effect of non-dominant resistance training on physical imbalance, and muscular function in unilateral athletes (badminton, tennis).

METHODS Fifteen male unilateral sports plyer were randomly divided into non-dominant resistance training group (NRTG, $n=8$ ) and control group (CG, $n=7$ ). Exercise program performed for 60 min(warm-up 10 min, main exercise $40 \mathrm{~min}$, cool down $10 \mathrm{~min}$ ), three times a weeks. The isokinetic muscular function of knee and shoulder joint was measured pre ( 0 week) and post ( 8 weeks).

RESULTS There was a significant different in isokinetic muscular function dominant and non-dominant $(p<.05)$. Non-dominant resistance training program was effective in isokinetic muscular function (peak torque $\% \mathrm{BW}$, Total work \%BW) in post- test than in pre-test $(\mathrm{p}<.05)$. And, was effective in improving shoulder joint isokinetic muscular function $600 / \mathrm{sec}$, peak torque $\% \mathrm{BW}$ (extension, flexion) in post- test than in pre-test $(p<.05)$. In addition, knee isokinetic muscular function 1800/sec total work \%BW (extension) the interaction effect was showed, and was effective $2400 / \mathrm{sec}$ total work \%BW (flexor) ( $\mathrm{p}<.05$ ).

CONCLUSIONS Non-dominant resistance training reduced right and left imbalances and improved isokinetic muscular function in unilateral athletes.

(c) The Asian Society of Kinesiology and the Korean Academy of Kinesiology
서론

운동 종목 중 테니스, 골프, 배드민턴 등은 허리를 회 전하고 어깨를 주로 이용하는 운동으로 한쪽을 극단적 으로 사용하는 편측 운동(unilateral exercise)이며[1], 이러한 특징 때문에 선수들의 통증과 부상 빈도가 높다 고 보고되고 있다[2]. 또한 신체적 불균형이 많은 편측 성 운동은 요추에 급격하고 강한 부하를 지속적으로 주 어 염좌(muscle strain), 요추 디스크 질환(disk), 면관 절 병변(facet syndrome)의 원인이 되며[3], 이는 관절

**Correspondence: Sunghwun Kang, Ph.D., Department of Sport Science, College of Art and Culture, Kangwon National University, 1 Kangwondaehak-gil, Chuncheon-si, Gangwon-do, Korea 24341.; Tel: +82 - 33 - 250 - 6780; Fax: +82 - 33 - 259 - 5680; E-mail: 94psycho@kangwon.ac.kr
의 가동범위와 능동적 움짐임의 제한을 가져와 경기력 을 저하시키며 더 악화되면 스포츠 손상으로 진행되어 경기를 수행할 수 없는 상태에 이르게 한다[4]. 편측 운 동 선수들의 골반과 체간의 불균형은 근력의 감소를 가 져오며 비대칭 정도가 $15^{\circ}$ 증가할 때 마다 최대근력은 8 9\% 정도 비율로 감소하는 것으로 보고되고 있다[5].

한편, 근력 불균형은 신체를 좌 - 우 또는 상 - 하로 구분할 때 동일한 근육간에 비정상적인 대칭이나 주동 근과 길항근 근력비율의 차이가 큰 것을 의미한다[6]. 이러한 근육의 불균형을 회복시키기 위해서는 근력운 동 프로그램, 스트레칭, 밸런스 트레이닝 등 종목의 특 이성을 고려하여 적절한 운동 프로그램을 실시 할 필요 
가 있다[7]. 선행연구에서 양측 운동은 균형성을 확보 하기 위해 근력의 평형성을 유지하려는 기전으로 우성 측 근력 향상에 부정적인 영향을 주는 것으로 보고 되 고 있다[8]. 이를 양측 운동손실(bilateral deficit)이라 고 하는데 대부분의 연구에서 편측저항운동에 양측 저 항운동이 양측 운동손실이 더 높게 나타난다고 보고하 고 있다 $[9,10]$. 반면 편측 저항운동에 실시 할 경우 코 어근육의 안정성과 높은 근활성도가 나타난다고 보고 하 였으며 [11], 열성측 하지의 근력과 파워 증가를 통해 양 쪽하지의 비대칭성을 교정함으로써 하지의 균형성 회복 에 도움을 줄 수 있다고 보고되고 있다[12]. 그리고 덤 벨을 이용한 솔더프레스 및 벤치프레스 운동 시 양측 운 동보다 편측 저항운동에서 코어근육 활성도가 높은 것 으로 보고하였으며 [13], 편측동작이 주를 이루는 스포 츠에서는 편측 저항운동을 주된 훈련 방법으로 채택해 야 한다고 보고되고 있다[14].

선행연구와 같이 편측운동 선수들을 대상으로 트레 이닝 효과를 검증하는 다양한 연구들이 진행 되고 있으 나, 편측운동 선수들에게 편측 저항운동을 적용한 연구 는 아직 미흡한 실정이며, 편측종목 선수들은 연습상황 에서의 체력보다는 기술 연습이 주류를 이루고 있는 실 정이다[15]. 하지만 최고의 컨디션 상태를 유지하기 위 해서 반드시 체력 훈련과 기술 훈련은 분리해서 실시해 야 하는 것이 효율적인 체력 향상에 도움이 될 것 이며 [16], 편측운동 선수들에게 체력훈련 시 편측 저항운동 이 병행된다면 더욱 효과적일 것으로 생각된다.

따라서 본 연구의 목적은 선수들의 관절이나 근육 손상의 예방과 재활에 있어 매우 효과적인 등속성 근력 측정 [17]을 활용하여 대표적인 편측종목 선수들인 테 니스와 배드민턴 선수의 근력 불균형 정도를 파악하고, 근력불균형 완화 전략인 열성측 저항운동의 실시가 신 체균형과 등속성 근기능에 어떠한 영향을 미치는지 규 명하고자 한다.

\section{연구방법}

\section{연구대상}

본 연구의 대상자는 H대학 소속의 편측종목 선수(테 니스, 배드민턴)로 5년이상 선수 경력이 있고 우성측이 오른쪽인(팔, 다리)자로 선정하였다. 본 연구의 목적을 충분히 설명하여, 이를 이해하고 연구 참여에 동의하는 지원자 중 15 명을 선발하여 열성측 저항운동그룹(nondominant resistance training group; NRTG, n=8)과 통제그룹(control group; CG, n=7)으로 무작위 분류하 였으며 신체적 특성은 <Table 1 >과 같다.

\section{실험설계 및 절차}

연구대상자들은 선정 전 간단한 신체적 특성(신장, 체중, 체지방률, 혈압), 설문 및 문진(병력사항, 선수경 력)을 실시하였다. 사전검사로 신체구성, 등속성 근기 능 검사를 실시 하였으며, 이후 8주간 주 3 회 열성측 저 항 트레이닝을 진행한 후 사전과 동일하게 사후검사를 진행하였다.

\section{측정항목 및 분석방법}

\section{신체구성}

신체구성은 생체전기저항 검사 장비 Inbody 720(Biospace, Korea)를 이용하여 측정하였으며, 사 전과 사후의 신장(Height), 체중(Weight), 체질량지수 (BMI), 체지방률 $(\% \mathrm{Fat})$ 을 측정하였다. 대상자들의 신 체구성은 <Table 1 >과 같다.

\section{등속성 근기능}

등속성 근기능은 Humac Norm(CSMI, USA)을 이 용하여 무릎관절과 어깨관절의 굽힘 근력, 폄 근력을 측정하였다. 측정 시 피험자는 최대 운동능력이 일어날 수 있도록 무릎관절 검사와 어깨관절 검사 운동을 각 검

Table 1. Physical characteristic of subjects

\begin{tabular}{cccccc}
\hline Group & Age (year) & Height $(\mathbf{c m})$ & Weight $(\mathbf{k g})$ & BMI $\left(\mathbf{k g} / \mathbf{m}^{2}\right)$ & body fat $(\%)$ \\
\hline $\begin{array}{c}\text { NRTG } \\
(\mathrm{n}=8)\end{array}$ & $21.88 \pm 0.99$ & $176.48 \pm 4.14$ & $72.96 \pm 8.67$ & $23.37 \pm 1.95$ & $17.69 \pm 3.90$ \\
$\begin{array}{c}\text { CG } \\
(\mathrm{n}=7)\end{array}$ & $21.14 \pm 1.07$ & $176.23 \pm 4.81$ & $79.29 \pm 12.09$ & $25.42 \pm 2.85$ & $23.30 \pm 5.78$ \\
\hline
\end{tabular}

Values are means \pm SD, NRTG; non-dominant resistance training group, $C G$; control group 
사 운동속도에서 최대하 능력으로 4 회 연습과정을 통해 숙달하도록 하였다. 등속성 최대 근력 측정은 $60 \% \mathrm{sec}$ 체중 당 최대근력 비율(percentage of peak torque to body weight)을 측정하였으며, 등속성 근지구력 측정은 $240 \% \mathrm{sec}$ 에서의 체중당 총 운동량 비율(percentage of total work to body weigh)을 측정하였다.

\section{운동 프로그램}

본 연구의 저항 트레이닝은 8주간 주 3회 60 분간 실 시하였으며 운동 프로그램은 체육과학연구원(현, 한국 스포츠정책과학원) 배드민턴과 테니스 선수 지도서를 참 고하였다 실험집단 트레이닝은 열성측 저항운동(Nondominant resistance training; NRT)은 상지, 코어, 하

\begin{tabular}{|c|c|c|c|c|}
\hline Wee & & \multicolumn{2}{|c|}{ Exercise Types } & Contents \\
\hline $\begin{array}{l}\text { Warm up } \\
(10 \mathrm{~min})\end{array}$ & & \multicolumn{3}{|c|}{ Jogging and whole body stretching } \\
\hline \multirow{9}{*}{$\begin{array}{l}\text { Main } \\
\text { Exercise } \\
\text { (40min) }\end{array}$} & & BT(3set) & NRT(1set) & \\
\hline & $\begin{array}{l}1-4 \\
\text { week }\end{array}$ & $\begin{array}{l}\text { - upper body } \\
\text { push-up } \\
\text { lateral raise } \\
\text { frontal raise } \\
\text { dumbbell row }\end{array}$ & $\begin{array}{l}\text { - upper body } \\
\text { one arm push-up } \\
\text { one arm lateral raise } \\
\text { one arm frontal raise } \\
\text { one arm row }\end{array}$ & $\begin{array}{l}6-8 \\
1 \mathrm{RM} \\
50 \sim 60 \%\end{array}$ \\
\hline & & - core & . core & \multirow{7}{*}{$\begin{array}{l}\text { 4set } \\
10-12 \\
1 \text { RM } \\
60 \sim 70 \%\end{array}$} \\
\hline & & plank & plank & \\
\hline & & deadlift & deadlift & \\
\hline & $5-8$ & back extension & back extension & \\
\hline & week & - lower body & - lower body & \\
\hline & & squat & one leg squat & \\
\hline & & $\begin{array}{l}\text { leg curl } \\
\text { leg extension }\end{array}$ & $\begin{array}{l}\text { one leg curl } \\
\text { one leg extension }\end{array}$ & \\
\hline \multicolumn{2}{|c|}{$\begin{array}{l}\text { Cool down } \\
\text { (10 min) }\end{array}$} & \multicolumn{3}{|c|}{ Walking and whole body stretching } \\
\hline
\end{tabular}

지로 트레이닝을 나누어 하루씩 진행하고, 기존에 실시 하던 양측 운동(bilateral training ; BT) 실시 후 편측 운동(unilateral training) $1 \mathrm{set}$ 를 추가하여 진행하였다. NRT운동은 1-4주에는 1RM 50 60\% 강도, 5-8주에 는 1RM 60 70\%강도로 실시하였다. 운동 프로그램은 $<$ Table 2> 과 같다.

\section{자료처리}

본 연구결과의 자료처리는 SPSS 23.0 통계프로그램 을 이용하여 열성측 저항운동 전 - 후 모든 변인에 있어 평균 $(\mathrm{M})$ 과 표준편차 $(\mathrm{SD})$ 를 산출하였다. 그룹 간(실험 집단, 통제집단), 시기 간(운동 전 vs 운동 후)트레이닝 에 따른 등속성 근기능의 차이를 검증하기 위해 이원분 산분석(Two-way ANOVA)을 실시하였다. 사후검증으 로 그룹 간 차이가 있을 시 독립 t-test를, 시기 간 차이 가 있을 시 대응 t-test를 실시하였다. 본 연구의 통계 학적 유의 수준은 $\mathrm{p}<.05$ 로 설정하였다.

\section{결과}

\section{트레이닝 전 열성측과 우성측의 근력 불균형}

트레이닝 전 연구 대상자들의 근력 불균형을 측정한 결과는 <Table 3 >과 같다. 어깨 폄근 $60 \% \mathrm{sec}$ 체중당 최대근력에서 유의한 차이가 나타났으며 $(\mathrm{p}<.05)$, 폄근 과 굽힘근의 $240 \% \mathrm{sec}$ 체중당 총일량에서 유의한 차이 가 나타났다 $(\mathrm{p}<.05)$. 무를 굽힘근의 $240 \% \mathrm{sec}$ 체중당 총일량에서 유의한 차이가 나타났다 $(\mathrm{p}<.05)$.

\section{트레이닝 후 열성측과 우성측의 근력 불균형}

열성측 저항운동 실시 후 연구 대상자들의 근력 불

Table 3. Results of isokinetic muscular function of non-dominant, dominant side

\begin{tabular}{|c|c|c|c|c|c|c|}
\hline & Group & & dominant & non-dominant & $\mathbf{t}$ & $\mathbf{p}$ \\
\hline \multirow{4}{*}{$\begin{array}{l}\text { Shoulder } \\
(\mathrm{Nm} / \mathrm{kg})\end{array}$} & $60^{\circ} / \mathrm{sec}$ & Extensor & $108.50 \pm 28.01$ & $88.63 \pm 21.26^{*}$ & 4.172 & .004 \\
\hline & $\mathrm{PT}(\% \mathrm{BW})$ & Flexor & $78.25 \pm 17.43$ & $74.38 \pm 12.26$ & .835 & .431 \\
\hline & $240^{\circ} / \mathrm{sec}$ & Extensor & $1525.88 \pm 590.14$ & $801.38 \pm 356.423^{*}$ & 4.527 & .003 \\
\hline & TW(\%BW) & Flexor & $1186.88 \pm 398.57$ & $783.38 \pm 243.01 *$ & 3.203 & .015 \\
\hline \multirow{4}{*}{$\begin{array}{c}\text { Knee } \\
(\mathrm{Nm} / \mathrm{kg})\end{array}$} & $60 \% / \mathrm{sec}$ & Extensor & $259.25 \pm 59.47$ & $255.50 \pm 56.63$ & .315 & .759 \\
\hline & $\mathrm{PT}(\% \mathrm{BW})$ & Flexor & $130.38 \pm 37.59$ & $130.75 \pm 39.22$ & -.053 & .959 \\
\hline & $240 \%$ sec & Extensor & $2088.88 \pm 483.37$ & $1899.88 \pm 355.12$ & 2.339 & .052 \\
\hline & TW(\%BW) & Flexor & $1164.88 \pm 382.26$ & $900.50 \pm 266.63^{*}$ & 4.210 & .004 \\
\hline
\end{tabular}

Values are means $\pm \mathrm{SD},{ }^{*} p<.05$ : dominant vs. non-dominant, \%BW: \% body weight, PT: peak torque 
Table 4. Change of isokinetic muscular function of non-dominant, dominant side after non-dominant resistance training

\begin{tabular}{lllllll}
\hline Group & & & dominant & non-dominant & t & p \\
\hline & $60 \% / \mathrm{sec}$ & extensor & $125.50 \pm 20.72$ & $110.13 \pm 21.22^{*}$ & .889 & .006 \\
shoulder & $\mathrm{PT}(\% \mathrm{BW})$ & flexor & $86.63 \pm 12.74$ & $85.88 \pm 17.80$ & .152 & .884 \\
$(\mathrm{Nm} / \mathrm{kg})$ & $240 \% \mathrm{sec}$ & extensor & $1213.38 \pm 706.27$ & $1889.25 \pm 450.35$ & 2.253 & .059 \\
& $\mathrm{TW}(\% \mathrm{BW})$ & flexor & $1445.13 \pm 285.75$ & $1276.25 \pm 203.87$ & 2.229 & .061 \\
& & extensor & $285.63 \pm 28.88$ & $290.50 \pm 22.34$ & -.491 & .639 \\
$\mathrm{knee}$ & $\mathrm{N} \% \mathrm{sec}$ & flexor & $156.88 \pm 27.49$ & $156.50 \pm 21.87$ & .048 & .963 \\
$(\mathrm{Nm} / \mathrm{kg})$ & $240 \% \mathrm{sec}$ & extensor & $2273.88 \pm 188.17$ & $2304.88 \pm 324.35$ & -.286 & .783 \\
& $\mathrm{TW}(\% \mathrm{BW})$ & flexor & $1612.63 \pm 290.35$ & $1620.63 \pm 283.75$ & -.086 & .934 \\
\hline
\end{tabular}

Values are means $\pm \mathrm{SD},{ }^{*} p<.05$ : dominant vs. non-dominant, \%BW: \% body weight, PT: peak torque

Table 5. Change of isokinetic muscular function of shoulder joint according to non-dominant resistance training

\begin{tabular}{|c|c|c|c|c|c|c|}
\hline Group & & & & pre & post & $\mathbf{F}$ \\
\hline \multirow{4}{*}{$60 \% / \mathrm{sec}$} & Extensor & \multirow{8}{*}{$\begin{array}{l}\text { Non- } \\
\text { dominant }\end{array}$} & NRTG & $88.63 \pm 21.26$ & $110.13 \pm 21.22^{*}$ & $\mathrm{G}: .566$ \\
\hline & PT(\%BW) & & CG & $88.00 \pm 20.34$ & $100.14 \pm 11.96$ & $\mathrm{G} \times \mathrm{T}: .440$ \\
\hline & Flexor & & NRTG & $74.38 \pm 12.26$ & $106.38 \pm 25.14^{*}$ & G : .301 \\
\hline & PT(\%BW) & & CG & $88.00 \pm 20.34$ & $100.14 \pm 11.96$ & $\begin{array}{l}\mathrm{T}: 10.724^{*} \\
\mathrm{G} \times \mathrm{T}: 2.170\end{array}$ \\
\hline \multirow{4}{*}{$240^{\circ} / \mathrm{sec}$} & Extensor & & NRTG & $801.38 \pm 356.42$ & $1889.25 \pm 450.35^{* \#}$ & G : $.4 .822^{*}$ \\
\hline & TW(\%BW) & & CG & $719.57 \pm 340.93$ & $1304.14 \pm 398.82$ & $\mathrm{G} \times \mathrm{T}: 2.672$ \\
\hline & Flexor & & NRTG & $783.38 \pm 243.01$ & $1276.25 \pm 203.87^{* \#}$ & G : $10.609^{*}$ \\
\hline & TW(\%BW) & & CG & $776.57 \pm 243.01$ & $721.29 \pm 253.34$ & GXT: $10.101 *$ \\
\hline
\end{tabular}

Values are means $\pm \mathrm{SD},{ }^{*} p<.05$ : pre vs. post, ${ }^{*} p<.05$ : NRTG vs. $\mathrm{CG}$, NRTG: non-dominant resistance group, $\mathrm{CG}$ : control group

Table 6. Chang of isokinetic muscular function of knee joint according to non-dominant resistance training

\begin{tabular}{|c|c|c|c|c|c|c|}
\hline & & Group & & pre & post & $\mathbf{F}$ \\
\hline \multirow{4}{*}{$60 \% / \mathrm{sec}$} & \multirow{2}{*}{$\begin{array}{l}\text { Extensor } \\
\text { PT(\%BW) }\end{array}$} & \multirow{8}{*}{$\begin{array}{l}\text { Non- } \\
\text { dominant }\end{array}$} & NRTG & $255.50 \pm 56.63$ & $290.50 \pm 22.34^{\#}$ & \multirow{2}{*}{$\begin{array}{l}\text { G: } 19.168^{*} \\
T: 1.908 \\
\text { GXT }: 1.128\end{array}$} \\
\hline & & & CG & $208.00 \pm 32.37$ & $212.57 \pm 35.61$ & \\
\hline & \multirow{2}{*}{$\begin{array}{l}\text { Flexor } \\
\text { PT(\%BW) }\end{array}$} & & NRTG & $130.75 \pm 39.22$ & $156.50 \pm 21.87^{\#}$ & \multirow{2}{*}{$\begin{array}{l}\text { G: }: 4.653^{*} \\
T: 1.336 \\
\text { GXT }: 1.995\end{array}$} \\
\hline & & & CG & $123.29 \pm 19.35$ & $120.71 \pm 22.90$ & \\
\hline \multirow{4}{*}{$240^{\circ} / \mathrm{sec}$} & \multirow{2}{*}{$\begin{array}{l}\text { Extensor } \\
\text { TW(\%BW) }\end{array}$} & & NRTG & $1899.88 \pm 355.12$ & $2304.88 \pm 324.35$ & \multirow{2}{*}{$\begin{array}{l}\text { G: } 1.665 \\
T: 6.353 \\
\text { GXT : .689* }\end{array}$} \\
\hline & & & CG & $1844.29 \pm 320.00$ & $2048.57 \pm 316.85$ & \\
\hline & \multirow{2}{*}{$\begin{array}{l}\text { Flexor } \\
\text { TW(\%BW) }\end{array}$} & & NRTG & $900.50 \pm 266.63$ & $1620.63 \pm 283.75^{*}$ & \multirow{2}{*}{$\begin{array}{l}\mathrm{G}: .005 \\
\mathrm{~T}: 6.810^{*} \\
\mathrm{G} \times \mathrm{T}: 6.810^{*}\end{array}$} \\
\hline & & & CG & $1250.86 \pm 428.51$ & $1250.86 \pm 505.45$ & \\
\hline
\end{tabular}

Values are means $\pm \mathrm{SD}$, ${ }^{*} p<.05$ : pre vs. post, " $p<.05$ : NRTG vs. $\mathrm{CG}$, NRTG: non-dominant resistance group, CG: control group

4 | The Asian Journal of Kinesiology 
균형을 측정한 결과는 <Table 4 >와 같다. 어깨 폄근 $60 \% \mathrm{sec}$ 체중당 최대근력에서만 유의한 차이가 나타났 으며 $(\mathrm{p}<.05)$, 다른 모든 항목에서 유의한 차이가 나타 나지 않았다.

\section{열성측저항운동에 따른 어깨 관절의 등속성 근기능의 변화}

어깨관절의 등속성 근기능의 변화를 측정한 결과는 <Table 5 >와 같다. 굽힘근의 $240 \% \mathrm{sec}$ 체중당 총일량 에서 그룹과 시기간 상호작용효과가 나타났다 $(\mathrm{P}<.05)$. 열성측저항운동그룹의 폄근과 굽힘근의 $60 \% \mathrm{sec}$ 체중 당 최대근력과, $240 \% \mathrm{sec}$ 체중당 총일량 모두 사전에 비 해 사후 유의하게 증가하였으며( $\mathrm{p}<.05)$, 폄근과 굽힘근 의 $240 \% \mathrm{sec}$ 체중당 총일량 모두 트레이닝 이후 집단간 유의한 차이가 나타났다 $(\mathrm{p}<.05)$.

\section{열성측저항운동에 따른 무릎 관절의 등속성 근기능의 변화}

무릎관절의 등속성 근기능의 변화를 측정한 결과는 <Table 6>과 같다. 폄근과 굽힘근의 $240 \% \mathrm{sec}$ 체중당 총일량에서 그룹과 시기간 상호작용 효과가 나타났다 (p<.05). 폄근과 굽힘근의 $60 \% \mathrm{sec}$ 체중당 최대근력에 서 트레이닝 이후 그룹간 유의한 차이를 나타냈으며, 열 성측저항운동집단의 굽힘 $240 \% \mathrm{sec}$ 체중당 총일량이 사 전에 비해 유의한 증가를 나타냈다 $(\mathrm{p}<.05)$

\section{논의}

본 연구는 편측종목운동선수(테니스, 배드민턴)을 대 상으로 우성측과 열성측의 근력 불균형을 확인하고 열 성측저항운동이 선수들의 근력불균형과 등속성 근기능 에 미치는 영향에 대한 결과를 다음과 같이 논의하고 자 한다.

본 연구 결과 우성과 열성의 어깨 비교에서 어깨 굽 힘근 $60 \% \mathrm{sec}$ 체중당 최대근력을 제외한 모든 항목에 서 우성측과 비교해 유의하게 낮은 것을 확인하였으며, 무릎 굽힘근의 $240 \% \mathrm{sec}$ 체중당 총일량 역시 우성에 비 해 낮은 것을 확인할 수 있었다. 이는 편측종목의 특성 상 불균형적인 훈련의 구성과 반복되는 편측훈련이 신 체의 근력불균형으로 이어진 결과로 판단된다. 선행연 구을 살펴보면, 편측운동선수(테니스, 배드민턴, 투척) 들의 상지와 하지 좌 - 우 근육량의 차이가 유의하게 나
타난 것으로 보고되고 있으며 [4], 우성측 팔이 열성측에 비해 삼두, 상완굴위, 상완신전위, 최대전완위 등에서 체 격의 변화 또는 변형이 큰 것으로 보고되어[18], 본 연구 결과를 뒷받침하고 있다. 즉, 반복적이며 지속적인 훈련 으로 인한 편측 부위의 과사용이 통증 발생가능성을 높 게 만들었으며, 만성화되어 가는 불균형적인 체형으로 인하여 경기력 저하로 연결될 것으로 생각된다. 따라서 이에 따른 보강운동의 중요성이 강조된다. 또한 무릎관 절 근력의 우성측과 열성측의 근력비율은 매우 중요한 요인으로 안정적인 근력의 비율은 무릎관절의 손상 예 방에 도움을 주는 것으로 보고되고 있다[19]. 선행연구 에서 고등학교 운동 선수를 대상으로 8주간 필라테스 프로그램을 실시한 결과 평형성 및 체형의 균형이 향상 되었으며 [2], 12 주간 좌우 부하를 달리한 배부 근육 교 정 프로그램 선수들의 좌 - 우 근육의 불균형을 감소시 켜 주는 것으로 나타났다[20]. 본 연구 결과 트레이닝 이후 어깨 폄근 $60 \% \mathrm{sec}$ 체중당 최대근력을 제외한 모 든 항목에서 열성측 저항운동 실시 이후 우성측과 열성 측의 근력이 통계적으로 유의한 차이가 나타나지 않아 선행 연구들과 일치하는 결과를 나타냈다.

근력과 근지구력은 스포츠 종목에서 경기력을 좌우 하는 기본적인 체력요소이며, 배드민턴의 경우 스매싱, 점프, 스텝 등 순간적인 동작들이 반복적으로 이루어지 기 때문에 강한 근력과 근지구력은 경기의 승패에 매우 밀접한 관계에 있다[21]. 또한 테니스 선수의 경우 주 사용 부위인 어깨 주변의 회전력과 요부근력, 슬관절 근 력은 경기력 개선과 관련이 있으며[22], 특히 어깨 관 절의 근력과 근파워가 우수해야 한다[23]. 등속성 근력 은 유동성 저항(accommodating resistance)을 통해 관 절의 가동범위 내 최대근력을 제공하며[24], 근력, 근 파워, 근지구력 등의 근기능을 한번에 운동에서 동시에 측정할 수 있어 근육의 기능 평가에 있어 기존의 방법보 다 객관성 있고 정확한 평가가 가능하다고 보고하고 있 다[25]. 또한 등속성 근기능 평가 시 총일량은 최대근 력과 높은 관련성이 있어[26], 함께 분석하는 것이 보 다 정확한 근력 예측에 도움이 될 수 있다[27]. 엘리트 선수를 대상으로 등속성 근력의 향상을 도모한 연구들 은 다양하게 진행되어 왔다. 태권도 선수를 대상으로 6 주간 플라이오메트릭을 실시한 결과 무릎 관절의 근기 능 향상을 보고하였으며 [28], 대학 테니스 선수를 대상 으로 밸런스 트레이닝 결과 하지 등속성 근기능의 유의 
한 향상을 보고하였다[29]. 또한 남자 카누선수를 대상 으로 서킷 웨이트 트레이닝 결과 견관절의 등속성 근력 $(60 \% \mathrm{sec})$ 과 근지구력 $(240 \% \mathrm{sec})$ 의 유의한 증가를 보고 하였다[30]. 하지만 본 연구 결과 열성측 저항운동그룹 의 어깨관절 체중당 최대근력 $(60 \% / \mathrm{sec})$ 과 체중당 총일 량에서 $(240 \% \mathrm{sec})$ 에서 사전에 비해 사후 유의하게 증가 하였으며, 어깨 폄근 체중당 총일량 $(240 \% \mathrm{sec})$ 에서 상 호작용 효과가 나타났다. 또한 무릎관절의 체중당 최 대근력 $(60 \% / \mathrm{sec})$ 에서 그룹 간 차이를 나타냈으며, 체중 당 총일량 $(240 \% \mathrm{sec})$ 은 상호작용 효과를 나타났다. 이 는 열성측 저항운동은 편측운동 선수들의 열성측 근력 향상에 효과적인 것으로 판단된다. 즉, 편측운동 선수들 은 비시즌 기간에 좌우 균형적인 근력을 나타낼 수 있도 록 열성측 저항운동이 요구된다.

위의 결과들을 종합해보면, 편측운동 선수들은 어깨 관절과 무를관절의 근육의 비대칭성을 가지고 있으며, 양측 저항운동 더불어 열성측 저항운동의 실시는 열성 측의 근력 비대칭성의 긍정적인 향상과 근력향상에 효 과적인 것으로 나타났다.

\section{결론}

본 연구결과 8 주간의 열성측 저항운동은 편측운동 선수(테니스, 배드민턴)의 근력 비대칭성과 등속성 근기 능에 긍정적 영향을 보여주었으며, 편측운동 선수들에 게 양측 저항운동뿐 아니라 열성측 저항운동을 실시한다 면, 부상방지와 체력요인 강화에 효과적인 방법으로 제 시된다. 또한 실전 경기력 테스트와 함께 진행된다면 더 욱 효율적인 피드백을 제공할 수 있을 것이라 생각된다.

\section{Conflicts of Interest}

The authors declare no conflict of interest.

\section{References}

1. Seo JY, Lee KS, Sin HS. The effect of unilateral muscular training the record improvement in swimming. Kor J Sports Sci. 2005; 14(2):729-735.

2. Yoon MJ, Kim KJ. Effect of pilates for the body balance, posture and pain in players of tennis, archery, and athletics. A J Kinesiol. 2012; 14(2):103-113.
3. Croisier JL. Muscular imbalance and acute lower extremity muscle injuries in sport. Int J Sport Med. 2004; 5(3):169176.

4. Howley ET, Franks BD. Health Fitness Instructor's Handbook Human Kinetics. 2003.

5. Park CK. The study of low back pain self-awareness scale and spinal lateral deformity between unilateral exercise athletics in adolescents. J Coach Dev. 2010; 12(3):139144.

6. Bettencourt CM, Jacobs K. Ergonomics for Therapists. Butterworth-Heinemann. 1995.

7. Skling C, Karlsson J, Thorstensson A. Hamstring injury occurrence in elite soccer players after preseason strength training with eccentric overload. Scand J Med Sci Sports. 2003; 13(4):244-250.

8. Cornwell A, Khodiguian N, Yoo EJ. Relevance of hand dominance to the bilateral deficit phenomenon. Eur J Appl Physi. 2012; 112(12):4163-4172.

9. Howard JD, Enoka RM. Maximum bilateral contractions are modified by neurally mediated interlimb effects. J Appl Physiol. 1991; 70(1):306-316.

10. Vandervoort AA, Sale DG, Moroz J. Comparison of motor unit activation during unilateral and bilateral leg extension. J Appl Respir Environ Exerc Physiol. 1984; 56(1):46-51.

11. Behm DG. Trunk muscle electromyographic activity with unstable and unilateral Exercises. J Strength Cond Res. 2005; 19(1):193-201.

12. Park ST. Effect of bilateral and unilateral resistance training using elastic band on functional fitness and fall efficacy in elderly women. J Kor Soc Liv Environ Sys. 2013; 20(5):655-662.

13. Saetebakken AH, Fimland MS. Muscle activity of the core during bilateral, unilateral, seated and standing resistance exercise. Eur J Appl Physiol. 2012; 112(5):1671-1678.

14. Park ST, Jung DJ. Effect of bilateral and unilateral resistance training on bilateral deficit of muscle strength in lower limb. Exerc Sci. 2008; 17(4):433-440.

15. Youn YK, Kim WB, Lim TH. Analytic hierachy process to examine factors influencing sports performance. Kor J 
Sport Psy. 2006; 17(1):1-11.

16. Sung BJ, Cho KH, Sung ES. Comparison of fitness levels of based on gender single and double national badminton player candidate. Kor J Mea Eva Physical Edu. 2016; 18(3):1-12.

17. Fatouros IG, Taxildaris K, Tokmakidis SP. The effects of strength training, cardiovascular training and their combination on flexibility of inactive older adults. Int J Sport Med. 2002; 23(2):112-119.

18. Kim HW. The comparison of the build on the arm between one-sided and both-sided athlete. J Sport Sci. 2013; 25:1-14.

19. Agaard P, Simonsen EB, Magnusson SP et al. A new concept for isokinetic hamstring: quadriceps muscle strength ratio. Am J Sports Med. 1998; 26(2):231-237.

20. Kim SE, Kim SG, Hong CM. Effect of 12 weeks back muscle asymmetry correction program on the body alignment of unilaterally developed badminton player. Kor J sport. 2017; (2):13-22.

21. Kuntze G, Mansfield N, Sellers W. A biomechanical analysis of common lunge tasks in badminton. J of Sports Sci. 2010; 28(2):183-191.

22. Kim HJ. A study on isokinetic strength and physical fitness of elite female tennis players in high school. Graduate School of Education. Chosun University.

23. Ryu GB. High school of tennis players and badminton players isokinetic that are shoulder and knees. Graduate
School of Education. Yeoungnam University.

24. Remaud A, Cornu C, Guével A. Agonist muscle activity and antagonist muscle co-activity levels during standardized isotonic and isokinetic knee extensions. J Electromyogr Kinesiol. 2009; 19(3):449-458.

25. Coburn JW, Housh TJ, Malek MH et al. Neuromuscular responses to three days of velocity-specific isokinetic training. J Strength Cond Res. 2006; 20(4):892-898.

26. Impellizzeri FM, Bizzini M, Rampinini E et al. Reliability of isokinetic strength imbalance ratios measured using the Cybex NORM dynamometer. Clin Physiol Funct Imaging. 2008; 28(2):113-119.

27. Kim MJ, Byun YH. Comparison on physical fitness and isokinetic strength in university badminton players and club students. Kor J Sports Sci. 2014; 23(4):1131-1142.

28. Singh A, Boyat AV, Sandhu JS. Effect of a 6 week plyometric training pro-gram on agility, vertical jump height and peak torque ratio of Indian Taekwondo players. Sport Exerc Med Open J. 2015; 1(2):42-46.

29. Lee WY, Hyun KS, Kim ML. Effect of tennis balance training for tennis players on balance ability and isokinetic muscular function of lower body. J Sport leisure Stud. 2016; 66:623-632.

30. Kang GY. The effect of circuit weight training o the improvement of isokinetic muscular cardiorespiratory function and blood component on canoe athletes. Kor J Phy Edu. 2016; 55(3):601-612. 